AUTHOR'S ABSTRACT OF THIS PAPER ISSUED

BY THE BIBLIOGRAPHIC SERVICE, OCTOBER 2

\title{
EXPERIMENTS ON THE METAMORPHOSIS OF NEOTENOUS AMPHIBIANS
}

\author{
W. W. SWINGLE \\ Osborn Zoölogical Laboratory, Yale University \\ TWO TEXT FIGURES AND TWO PLATES (EIGHT FIGURES)
}

The discovery of the causal relationship existing between certain endocrine secretions and amphibian metamorphosis has served to stimulate anew the interest of investigators in the problem of neoteny and paedogenesis as presented by various species and genera of this vertebrate group.

The retention of the larval form either permanently or for periods far beyond the normal time required for metamorphosis is known as neoteny or neotenie (Kollmann, '82). This author, who has studied the problem carefully, distinguishes between partial neoteny, where the animal is simply retarded in metamorphosis beyond the normal time and passes the winter as a tadpole, and total neoteny in which case the animal retains its gills and other larval characters becoming sexually mature in this condition.

Partial neoteny is quite common in such frog species as $R$. clamata and $R$. catesbeiana as there is a pronounced tendency of these forms to prolong the larval life an extra six or eight months beyond the usual one- and two-year period. Indeed, the larval life of Rana catesbeiana may extend to the period of sexual maturity in some tadpoles in so far as the possession of ripe spermatozoa is concerned, and this appears to be the explanation of the second larval sexual cycle described by the writer in a previous paper ('21).

The classical example of total neoteny is axolotl, the paedogenetic larva of Amblystoma tigrinum. The researches of Duméril ('65), Chauvain ('75) and others on the metamorphosis of axolotl have resulted in the more or less current belief that the 
peculiar group of aquatic amphibians known as perennibranchiates (Necturus, Proteus, Typhlomolge, etc.) are permanent larval forms capable of reproducing the species. The group is supposed to represent a sort of retrograde evolution from an originally terrestrial life to permanent aquatic existence by suppression of metamorphosis. The evidence for this view is suggestive; briefly stated it is somewhat as follows:

1. It is generally conceded that the perennibranchiates do not form a natural group, but are to be regarded as a heterogeneous assembly; various genera are undoubtedly represented in the group. These animals probably became neotenic at a phylogenetically old stage and are hence the oldest and not the youngest members of the present-day urodeles.

2. Various anatomical features of the group, such as the pentadactyloid limb, presence of lungs, suppression of internal gills, and connection of the pelvic girdle with the vertebral column, point to a terrestrial existence somewhere in the history of the group.

3. Perhaps the most suggestive line of evidence for the view that the perennibranchiates are permanent larval forms is the occurrence of neoteny and paedogenesis as aberrations of development in semiterrestrial species of urodeles. For instance, it has long been known that the larvae of certain European salamanders fail to undergo metamorphosis and occasionally attain the size of $80 \mathrm{~mm}$., whereas the normal size at transformation is $40 \mathrm{~mm}$. Larvae of Triton have been reported 80 to $90 \mathrm{~mm}$. long with functional gills and sexual organs fully developed. DeFilippi ('61) found in one locality in Lombardy sexually mature larvae. According to him, such gill breathing, sexually mature specimens occur constantly in a small lake in the province of Ossola in the Italian Alps. Many other cases have been reported, and the classical example of the axolotl is well known. It will be recalled that this creature was classified by systematists as a distinct species of perennibranchiata until Duméril described its metamorphosis into Amblystoma tigrinum.

4. Lastly, it has been repeatedly stated in the literature that one of the perennibranchiates, Typhlomolge, is hereditarily 
lacking in the thyroid apparatus, which, if true, accounts for the suppressed metamorphosis. It will be recalled that it is possible to induce neoteny in anuran larvae by thyroid extirpation.

This evidence is suggestive, and taken in conjunction with what we know of the thyroid gland and its relation to metamorphosis suggests that the thyroid mechanism of forms such as Necturus, axolotl, and neotenous anuran larvae is defective and incapable of bringing about transformation.

\section{EXPERIMENTS ON PERENNIBRANCHIATES (NECTURUS MACULATUS)}

A group of adult necturus were obtained from the Ohio Valley and repeatedly injected with thyroid extract, and at the same time forcibly fed large quantities of the desiccated commercial preparation by means of a long glass pipette thrust down the throat. This procedure was repeated several times with negative results, despite the fact that the thyroid dosage was relatively enormous. The physiological activity of the thyroid preparation was tested by feeding small amounts to larvae of $\mathrm{R}$. clamata, averaging $50 \mathrm{~mm}$. total length, but without hind legs. These animals promptly showed marked indications of metamorphosis within eight days from the date of feeding (fig. 7). The iodine content of the desiccated tissue was given on the label of the bottle as 0.21 per cent by weight and the analysis made by the chemists of Parke, Davis \& Company, Detroit. It is obvious that the thyroid preparation used in the experiment was not responsible for the negative results. One animal was injected twice intraperitoneally with $10 \mathrm{mg}$. of thyroxin iodine obtained from the laboratories of E. R. Squibb \& Sons, and then forcibly fed large quantities of desiccated thyroid and anterior pituitary lobe substance. The physiological activity of the thyroxin iodine was tested by placing two young specimens of Amblystoma punctatum in a 1 to 50,000 solution, whereupon they metamorphosed within two weeks. None of these agents, singly or taken together, produced the slightest indications of metamorphosis, nor, I may add, appeared to harm the Necturus in any way. As a last resort, three thyroid glands of newly metamorphosed 
Rana clamata frogs were engrafted subcutaneously in one animal. Four months later, no metamorphic changes had appeared. The experiment was abandoned, with the conviction firm in the writer's mind that, although adult Necturus may possibly be induced to metamorphose, thyroid tissue alone is not the agent that will accomplish the transformation. Axolotls readily respond to thyroid administration by metamorphosis according to Laufberger ('13) (cited by Adler, '16), Huxley ('20), and others.

Examination was made of the thyroids of untreated Necturus, but nothing unusual was observed, except that in some animals the glands are small and the vesicles more or less isolated from each other, while in other animals the glands may be large. The blood supply appeared normal in those individuals with compact glands. The thyroid of one animal consisted of but four to six extremely large follicles on either side, in others the gland was larger and comprised ten to sixteen large follicles, while in one animal the glands consisted of twenty-one or twenty-two follicles on each side. In the last-mentioned case the animal had been treated with thyroid and thyroxin iodine several weeks previous to examination.

In order to test the physiological activity, a series of heteroplastic thyroid transplantation experiments were made. In the first set of experiments one-half of the thyroid gland (from one side only) was engrafted intraperitoneally into immature Rana clamata tadpoles averaging $52 \mathrm{~mm}$. total length, with hind-leg buds $2.7 \mathrm{~mm}$. long, but undifferentiated. Within eight days the tadpoles which received the graft showed all the symptoms of hyperthyroidism. The animals were greatly emaciated, with protruding eyes; the hind legs increased in length from $2.7 \mathrm{~mm}$. to $8 \mathrm{~mm}$. with complete differentiation. In two animals the right fore leg had appeared and the tail atrophied to half its original length. At the end of the eighth day from the date of transplantation the larvae measured $26 \mathrm{~mm}$. total length, whereas the week previous the same individuals averaged $52 \mathrm{~mm}$. It was impossible to keep the tadpoles alive until they completely metamorphosed, so great was the acceleration of metabolism and metamorphic change. Death in most cases was apparently 
due to respiratory difficulties. Several tadpoles were kept alive until tail resorption was nearly complete by placing them in shallow containers and passing a stream of compressed air through the water.

In a later series of experiments the thyroids were cut into small pieces and each part transplanted separately into immature tadpoles without hind limbs. One animal received three large colloid-filled vesicles dissected out of the gland; another received four follicles; the remainder received seven large follicles each. The grafts were made July 26th, and on July 30th, when examined, several engrafted individuals showed evidences of hyperthyroidism, such as emaciation and limb development. By August 2nd all of the animals showed a marked reaction to the graft; emaciation was very marked, the eyes protruded, and the legs had greatly increased in length. One animal had the right fore leg through the skin, and the remainder showed autolysis of the skin in the region where the fore limb later appears. The control animals remained unchanged (figs. 3 to 6). August 7 th, when the experiment was discontinued, all engrafted animals were in advanced stages of metamorphosis. During the course of the experiment the animals were fed quantities of Spirogyra. They fed very little after the first three or four days, and not at all following the onset of marked metamorphic change.

This experiment shows clearly that the thyroid glands of adult Necturus are highly active metamorphosis-inducing agents. It is reasonable to assume that if they are capable of producing marked metamorphic changes when transplanted into immature anuran larvae within eight days, they are potentially competent of doing likewise in Necturus if this animal still retained any capacity to transform. It will be shown later that the relation of the thyroids to metamorphosis in Necturus is quite different from the situation existing in axolotls and neotenous anurans.

While writing this paper the writer came upon a statement by Uhlenhuth ('21) that Jensen ('14) had subjected Proteus to the action of thyroid substance, but did not get any demonstrable results. Uhlenhuth's comment upon this experiment is interesting. He says: "Many causes may have been responsible for this 
failure (i.e., Jensen's), in particular the fact that the animals were too old when they were subjected to the thyroid feeding." And elsewhere the same author states "that nothing is known of the endocrine system of Proteus."

The writer ventures to predict that if the thyroid glands of an untreated Proteus are engrafted into anuran larvae, the latter will react similarly to those engrafted with Necturus glands. These experiments negative any such assumption as Uhlenhuth's ('21, page 201) that, "if the thyroid substance is capable of causing the development of the characters of a terrestrial amphibian, the administration of thyroid substance should cause the metamorphosis of Proteus anguineus." This writer apparently holds the view that any perennibranchiate will, if fed thyroid, metamorphose, and that retention of larval characters in these forms is due to absence or defect of the thyroid mechanism. The present experiments lend no support to any such hypothesis. In regard to the statement that the endocrine system of Proteus is unknown, it is interesting to note that Franz Leydig in 1853 (p. 62), describes the thyroids of this animal. According to his description, they apparently do not differ greatly from those of Necturus.

Uhlenhuth lays great emphasis upon the fact that one of the perennibranchiates, Typhlomolge rathbuni, is said to lack the thyroid gland, and states in effect that the reason for the retention of the larval characters is due to the thyroid absence. Perhaps this is true, but it strikes the writer as being rather odd that the retention of larval characters of this perennibranchiate should depend upon the absence of the thyroid function, and that such characters are retained in another form (Necturus) in spite of the presence of a most potent and active thyroid, in spite of feeding, injecting, and engrafting of thyroid substance.

There is another point of interest in connection with the discussion of Typhlomolge, and that is the apparent absence of thyroid glands in adults of this peculiar animal. Emerson ('05) studied the general anatomy of two specimens preserved in 4 per cent formalin, and merely mentions in the course of her discussions, "Sections of the head reveal the presence of a thymus 
gland, but I do not find thyroids." This is the only mention made of the thyroids in her paper. Recently, through courtesy of Prof. H. H. Wilder, the writer had an opportunity of examining Miss Emerson's material, consisting of serial sections through the head of one animal. No trace of a thyroid was observed, but it should be stated that some of the epithelial structures had disappeared.

The writer has carefully examined three adult specimens of Typhlomolge and failed to find any trace of a thyroid. The entire lower-jaw region, back to and including the heart, was dissected under a high-power binocular microscope, and some tissue sectioned, but with negative results. However, the failure to find the glands does not necessarily mean that they were not present or had not been present at some period, because the animals had been preserved over fifteen years in alcohol and many of the epithelial structures had undergone disintegration during this interval.

If the thyroid mechanism of Typhlomolge is congenitally lacking, then this amphibian is the only vertebrate known in which the gland is normally absent. It has been stated in the literature that Typhlomolge is only the neotenic larva of Spelerpes, but it is well known that Spelerpes larvae possess thyroids. It seems probable that the Texas cave salamander has a thyroid, but that it develops as a diffuse aggregation of follicles, somewhat similar to the condition known to exist in teleosts. At any rate the question of the presence or absence of the gland deserves further investigation before it can be accepted as an established fact, because the history of vertebrate morphology is replete with descriptions of forms supposedly anomalous for the lack of certain structures, only to be later shown to possess them.

To sum up, it may be said that these experiments indicate that Necturus and probably other perennibranchiates have permanently lost their ability to metamorphose into terrestrial forms under the stimulus of thyroid administration alone: our experiments indicate that the thyroid apparatus of these animals is highly active and potent despite their larval characters. 
These experiments, however, do not rule out the possibility of inducing the metamorphosis of perennibranchiates by other means than that of thyroid feeding or transplantation. The cause of the non-metamorphosis of these forms may be pluriglandular in origin, and a result of defective interrelation of various endocrine glands. It should be added that the writer fed one Necturus small quantities of desiccated ovarian, testicular, adrenal, and anterior pituitary lobe tissues, along with large quantities of thyroid extract, but without avail. It is probable that transplants of these various glands simultaneously would have had more effect than feeding the desiccated substances, in case the animal possessed the capacity to transform. Administration of endocrine secretions, no matter in what quantity given, can give positive results only when acting upon an appropriate hereditary substratum. The indications are that the hereditary factors concerned in the metamorphosis of Necturus have become so modified that the appropriate substratum is lacking, thus rendering the thyroid hormone powerless. It is obvious that hereditary conditions in the perennibranchiates are quite different from those in axolotl, in regard to metamorphosis, since the latter readily respond to thyroid feeding and the former do not.

\section{EXPERIMENTS WITH AXOLOTL THYROIDS}

Through the courtesy of Prof. Henry Laurens, of the Department of Physiology, the writer obtained a very large specimen of Axolotl mexicanum (neotenic larva of Amblystoma tigrinum) for thyroid transplantation work. The animal was a very large one, measuring 14.25 inches from snout to tail-tip. The exact age of the specimen is unknown, as it was obtained, along with several others, from Albuquerque, New Mexico. When first brought to the laboratory the animal was about 8 inches long, and hence presumably about two years of age at the time; it was kept under laboratory conditions for two more years, thus making four years the animal's approximate age when used by me. This specimen was the only one of the lot that failed to metamorphose within a few months following removal from its native habitat to New Haven. 
The thyroid glands were compact and large-larger than the glands of newly metamorphosed R. clamata frogs-and made up of large and small follicles filled with colloid. The blood supply to the glands was rich, apparently much more so than is the case with larval anurans; only a superficial examination was made to test this point because of the lack of sufficient material.

The pituitary gland was also examined; the pars anterior seemed normal or possibly rather small when the relative sizes of all the lobes are considered.

The thyroids were dissected out and each gland cut into three pieces of approximately equal size. Each piece of tissue was then transplanted intraperitoneally into immature Rana clamata larvae averaging $51.5 \mathrm{~mm}$. total length with hind-leg buds 2.2 $\mathrm{mm}$. undifferentiated. A few hours following grafting one tadpole jumped out of the container and was found dead, leaving but five transplanted tadpoles. Eight days after transplanting the pieces of axolotl thyroid, the engrafted tadpoles showed all the characteristic features of hyperthyroidism, such as cessation of growth, marked acceleration of limb development, tail atrophy and resorption, and body emaciation.

August 20th, or twelve days after transplantation, four of the engrafted animals were found dead (figs. 8 to 10). The photographs show very well the marked tail atrophy and resorption and the fore-leg development. The early death of the animals was due to the great acceleration of metabolism and metamorphic change. Undoubtedly, smaller pieces of the axolotl thyroid would have had the same effect upon metamorphosis without the too destructive rise in katabolic activity. The amount of tail resorption can be judged by the fact that during the twelve days of the experiment the average total length of the tadpoles decreased from $51.5 \mathrm{~mm}$. to $29.6 \mathrm{~mm}$. The control animals remained unchanged. ${ }^{1}$

${ }^{1}$ Since this was written one hundred and nine large axolotls were obtained by Professor Harrison from Albuquerque, New Mexico, and given to me for experimentation. This experiment was repeated on a large scale with identical results. Mr. Carl Mason, of this laboratory, metamorphosed thirteen normal, thyroidless, and pituitaryless $R$. sylvatica tadpoles by transplanting pieces of the thyroid of a single 14-inch axolotl. 
The pituitary gland of the axolotl was also engrafted into an immature larva of $R$. clamata, measuring $45 \mathrm{~mm}$. total length, hind limbs $2.5 \mathrm{~mm}$. long and differentiated into thigh and shank, but without toe points. All three lobes of the gland were transplanted together. The success of the graft was attested by the color change in the larva induced by the expansive action of the pars intermedia secretion upon the melanophore system.

Eighteen days after the graft was made the animal had not changed in any way either in regard to limb development or growth, so the experiment was abandoned. Examination of the implanted gland showed it to be mostly resorbed.

The negative result following grafting of the axolotl pituitary is in striking contrast to that obtained when the pituitary of a newly metamorphosed frog is transplanted into immature anuran larvae. However, it must be remembered that in the latter case we are dealing with a homoplastic graft and in the former with a heteroplastic one, and a single transplant at that. It is unfortunate that a larger amount of axolotl material was not available, for it is of importance to know whether or not the pituitary gland of the axolotl is active, and some idea of its potency can be obtained by testing its effect upon limb development of anurans. If the results are consistently negative, then it is probable that the gland is defective in so far as its relation to the thyroid mechanism is concerned.

The results obtained by grafting portions of axolotl thyroids, are clear-cut and admit of but one interpretation: namely, that the thyroid apparatus of this animal is highly active and potent in inducing marked metamorphic change when transplanted into immature anurans, but is apparently incapable of initiating metamorphosis when left unmolested in its normal place. This experiment seems to rule out the idea that the axolotl's thyroid secretion is defective. If the thyroid glands of a single axolotl when cut into six fragments are capable of initiating metamorphosis in five anuran larvae grafted with a single fragment (the sixth animal died) within ten to fourteen days, surely we may safely assume that the same glands, entire, contain enough of the active hormone to initiate metamorphosis in the single axolotl of which 
they originally formed a part. The metamorphosis of an anuran larva involves much more fundamental transformation and reorganization of tissues and organs than the same process in axolotl.

Our experiment suggests four possible factors to account for this anomalous situation: 1) Possibly the blood supply taking the hormone away from the gland is defective and the thyroid consequently unable to release its secretion. 2) The thyroid is able to collect, store, and transform the incoming iodine taken from the food and water into the physiologically active hormone, but owing to defective nervous stimulation the gland is unable to release the secretion into the blood stream. 3) The secretion, though perfectly formed, is unable to escape from the gland, owing to some defective interrelation between the pituitary and thyroid, or possibly some other endocrine gland which supplies the necessary stimulus to the thyroid, thereby acting as the releasing factor. 4) The blood and tissues of neotenous forms may contain substances that neutralize or render impotent the metamorphosis-inducing agent of the thyroid hormone.

If it is true, however, that the thyroid hormone is unable to escape because of defective outlet through the blood stream, or because of defective interrelationship between various components of the endocrine system, how is it that axolotls usually promptly metamorphose when taken from their native habitat or when subjected to sudden environmental changes, such as a change from New Mexico to New Haven?" Furthermore, aside from the nervous system, there are few anatomical or physiological mechanisms which hold such power over other structures as to permit a gland like the thyroid to manufacture and store in large quantities a highly complex substance, but apparently prohibits its release. When we consider the thyroid glands of an axolotl filled to capacity with highly active secretion, as our experiments clearly show, yet apparently unable to release the

\footnotetext{
2 Of the 109 axolotls received from Albuquerque, only those that were thyroidectomized failed to metamorphose spontaneously a few weeks after removal from their native habitat. Left unmolested in the New Mexican environment, the animals may remain permanent larvae and grow to a length of 14 inches.
} 
hormone into the network of capillaries surrounding the gland in sufficient quantities to induce transformation, we are led to the conclusion that in the last analysis the crux of the problem is defective stimulation (perhaps inhibition) of the gland by that portion of the animal's nervous system responsible for the flow of secretion under normal conditions.

How else can one reduce to harmony the multiplicity of factors that have been invoked to explain axolotl metamorphosis, save by reducing them all to a common factor: i.e., agents which produce their effect by subjecting the organism to more or less violent changes of the environment thus acting as a constant nervous stimulant? For example, a few of the agents (aside from thyroid or iodine feeding) ${ }^{3}$ that have served to initiate axolotl metamorphosis are: sudden changes in food supply, drying of swamps or pools in which the animals live, changes in the temperature of the water (Shufeldt, '85); forcing the animals to breathe air, insufficiently aerated water (Chauvin, '75, '77); administration of salicylic acid (Kaufman, '18); shifting of the animal from its normal habitat to other districts, such as from New Mexico to New Haven.

A glance at this list of factors indicates that their varied nature alone negatives the idea that any one of them can be the real causative factor in axolotl metamorphosis. However, all can be classed as shocks to the organism, and it may possibly be that such more or less constant excitation may bring about nervous stimulation to the thyroid sufficient to overcome the inhibiting influence and release the stored secretion, thus initiating metamorphosis. The nature of the inhibiting factor is of course the crux of the problem, and in the last analysis is probably of endocrine origin acting through the intermediation of the nervous

${ }^{3}$ Apropos of Uhlenhuth's claims that iodine has nothing to do with axolotl metamorphosis, the recent papers of Jensen and Hirschler are of interest. Jensen (Compt. Rend. Soc. de Biol., T. 85, 1921) metamorphosed axolotls by injections of jodocasein, iodoserumglobulin, and iodoserumalbumin. Also by feeding with an organic iodine compound--iodo-thyrosin. Hirschler (Arch. Entw. Mech., 1922) metamorphosed axolotls and anuran tadpoles by feeding elemental iodine in various forms. These investigators worked on strains of axolotls which do not spontaneously transform. 
system. On theoretical grounds, the writer believes that electrical stimulation, thyroid puncture, and extirpation of the thyroid and reimplanting it into the same individual will metamorphose axolotl, but to date has been unable to obtain sufficient animals for experimentation along the lines indicated.

If such procedure should cause metamorphosis, then it is clear that the physiologically active hormone is not released from the thyroid in sufficient quantity to induce transformation. From the evidence at hand it seems to the writer that such is probably the case. Axolotls readily respond to thyroid feeding or to injections of iodothyrine by transforming, and the amount of thyroid substance required is not excessive. If the assumption were correct that the blood and tissues of this neotenic form contained substances which neutralized or rendered impotent the thyroid hormone, thus preventing metamorphosis, why should small amounts of thyroid substance, when fed, be able to produce an effect? The evidence obtained from thyroid transplantation experiments with neotenous anurans is interesting in this connection.

\section{EXPERIMENTS WITH THE THYROIDS OF NEOTENOUS ANURANS}

The larvae of the green frog, Rana clamata, have a larval period of approximately one year: i.e., 370 to 400 days from the date of egg deposition. The animals attain a length of about $65 \mathrm{~mm}$. at metamorphosis, which occurs in late July and early August. However, it has been repeatedly observed by the writer that many larvae fail to transform at the usual time and remain an extra year as tadpoles. Such animals are typically neotenous forms and, as they continue growing throughout the larval period, they ultimately reach a size considerably in excess of that generally exhibited by the species at metamorphosis. Larvae measuring 75 to $90 \mathrm{~mm}$. total length, with differentiated hind legs varying from 4 to $20 \mathrm{~mm}$., have been captured in the months of November, December, and January from various pools in the vicinity of New Haven. The tendency of the species is to prolong rather than curtail the span of larval existence. Because of this fact, a series of thyroid-transplantation experi- 
ments were carried out with these neotenous individuals, in the hope of determining the endocrine locus responsible for the failure to metamorphose at the proper time. The first procedure was to test the physiological activity of the thyroid apparatus of such animals by transplanting the glands into immature larvae of the same species with undifferentiated legs and noting the effect upon metamorphosis.

December 17, 1920, three immature larvae, averaging $33.5 \mathrm{~mm}$. total length, without hind limbs, except undifferentiated epithelial buds, were engrafted with the thyroid glands of $80-\mathrm{mm}$. neotenous larvae with hind legs $11.6 \mathrm{~mm}$. long. The engrafted forms were the smallest obtainable at this season of the year and not over six months of age. It is unfortunate thatalarger number could not have been used, but the results are clean-cut, as will be seen later, when the experiment was rechecked with another group of animals in midsummer.

One animal was in advanced stages of metamorphosis on January 17th, just one month from date of grafting. The right fore leg was through the skin and the left fore leg appeared the day following (January 18th). For a week previous to the first appearance of the fore limbs the engrafted animal showed marked signs or hyperthyroidism, such as emaciation, protrusion of the eyes, slight tail atrophy, and autolysis of the skin over the region of the fore legs. The control larvae at this time averaged 34 to $38 \mathrm{~mm}$. in length and showed no change in regard to leg development from the condition when the experiment was started. The other two larvae of the engrafted culture developed fore limbs January 22nd and typical frog mouth. All of the animals died before tail resorption was complete. Figure 1 is a drawing of an engrafted larva and its control. Figure 2 shows the neotenous type of tadpole from which the thyroid glands were taken. Generally the limb development is less marked than the drawing indicates. When the drawings were made the animals were nearly a year past their normal time of metamorphosis.

Briefly summarized, the experiment shows that transplantation of the thyroid glands of neotenous larvae $80 \mathrm{~mm}$. total length, with differentiated hind limbs $11.6 \mathrm{~mm}$., into immature tadpoles 
$33.5 \mathrm{~mm}$., without limbs, brings about very marked metamorphic changes within thirty days, although the animals could not be reared to the stage of complete tail resorption.

It was observed that in the engrafted animals autolysis of the skin over the region of the fore limbs occurs independently of limb development as a distinct phenomenon of anuran metamorphosis. Years ago Braus ('06) described similar phenomena in developing tadpoles after extirpation of the limb bud. I mention it here because of the remarkable autolysis which is sometimes observed in transplanted larvae; the fore limbs may be small, whereas the skin area destroyed may be very large indeed compared with limb size. It should be remembered, however, that in anurans the fore and hind legs tend to keep pace with one another in development, only the fore legs are not visible because of the opercular covering.

The chief point of interest, however, is the odd fact that much greater metamorphic change follows transplantation of the thyroids of $80-\mathrm{mm}$. neotenous larvae with hind legs $11.6 \mathrm{~mm}$. into immature larvae without limbs than occurs in control animals $80 \mathrm{~mm}$. with legs $11.5 \mathrm{~mm}$. In other words, the grafted glands wrought far greater changes in the same time interval (approximately one month) when transplanted into immature larvae than when left undisturbed in the mature forms.

This result, so curious and at variance with what one might expect, led to a repetition of the same experiment the following summer, from a different angle. Immature larvae averaging 40 $\mathrm{mm}$. total length with hind leg buds $0.5 \mathrm{~mm}$. were transplanted with the thyroids of mature though not neotenous tadpoles $68 \mathrm{~mm}$. total length with hind legs $11.5 \mathrm{~mm}$. The results were similar to those of the earlier experiments, though not so striking as one would expect, because the mature control animals (not neotenous) in this experiment were approaching metamorphosis at the end of the experiment, whereas in the previous experiment the neotenous controls showed no change, and in fact passed the winter in the laboratory as tadpoles.

The experiments indicate that the thyroids of extra-season, neotenous anuran larvae with hind limbs $11 \mathrm{~mm}$. long are physio- 
logically active and capable of inducing metamorphosis, provided their contained secretion could get into the blood stream. Like the thyroid mechanism of axolotl, the glands of these larvae seem to be rendered more or less functionless by an inhibiting factor which prevents secretion of the hormone into the circulation. Following transplantation, the inhibition apparently is overcome by the acquisition of a new blood and nerve supply

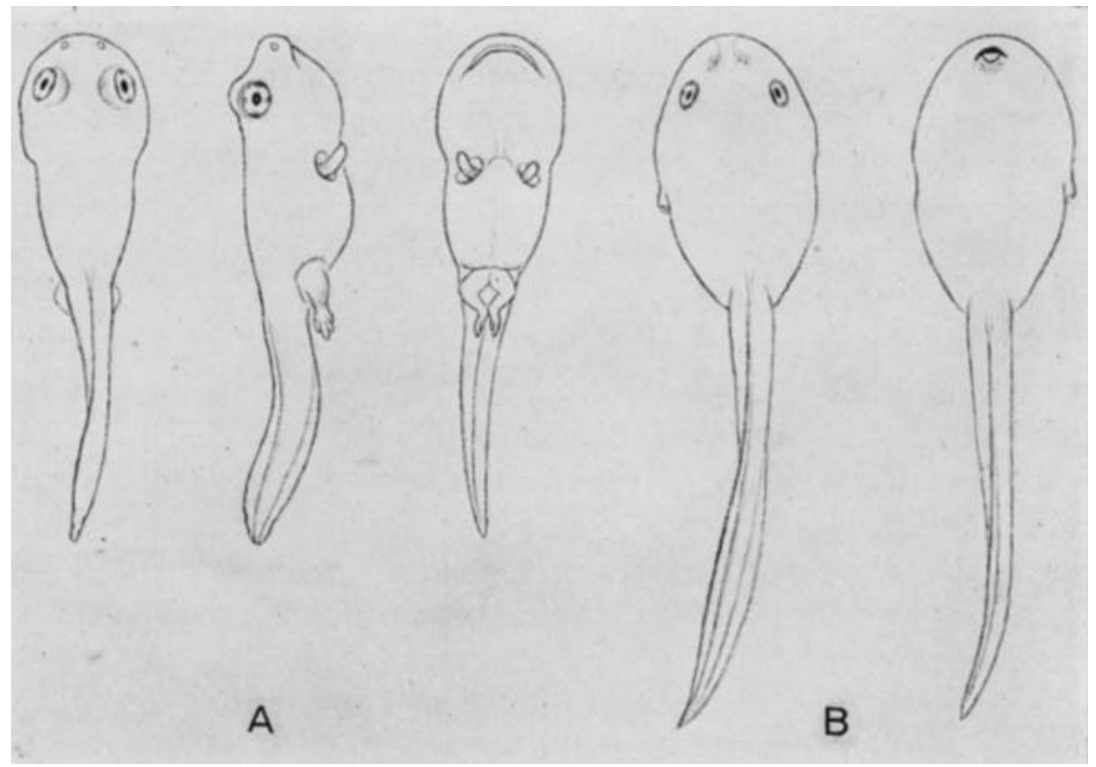

Fig. 1 Immature R. clamata larvae engrafted with the thyroids of extra large neotenous tadpoles with hind limbs $11.6 \mathrm{~mm}$. long, B, immature control animals of A groups. $\times 2$.

in the new environment, because the absorbed secretion induces metamorphosis.

A modification of the experiment just recorded was attempted; the thyroids of large neotenous larvae were engrafted intraperitoneally into other extra-season animals of the same size and developmental stage. The idea was, that since the glands of such individuals are physiologically active and capable of 
inducing marked metamorphic changes when transplanted into immature animals, they would probably produce similar effects in neotenous larvae while undergoing resorption in the foreign

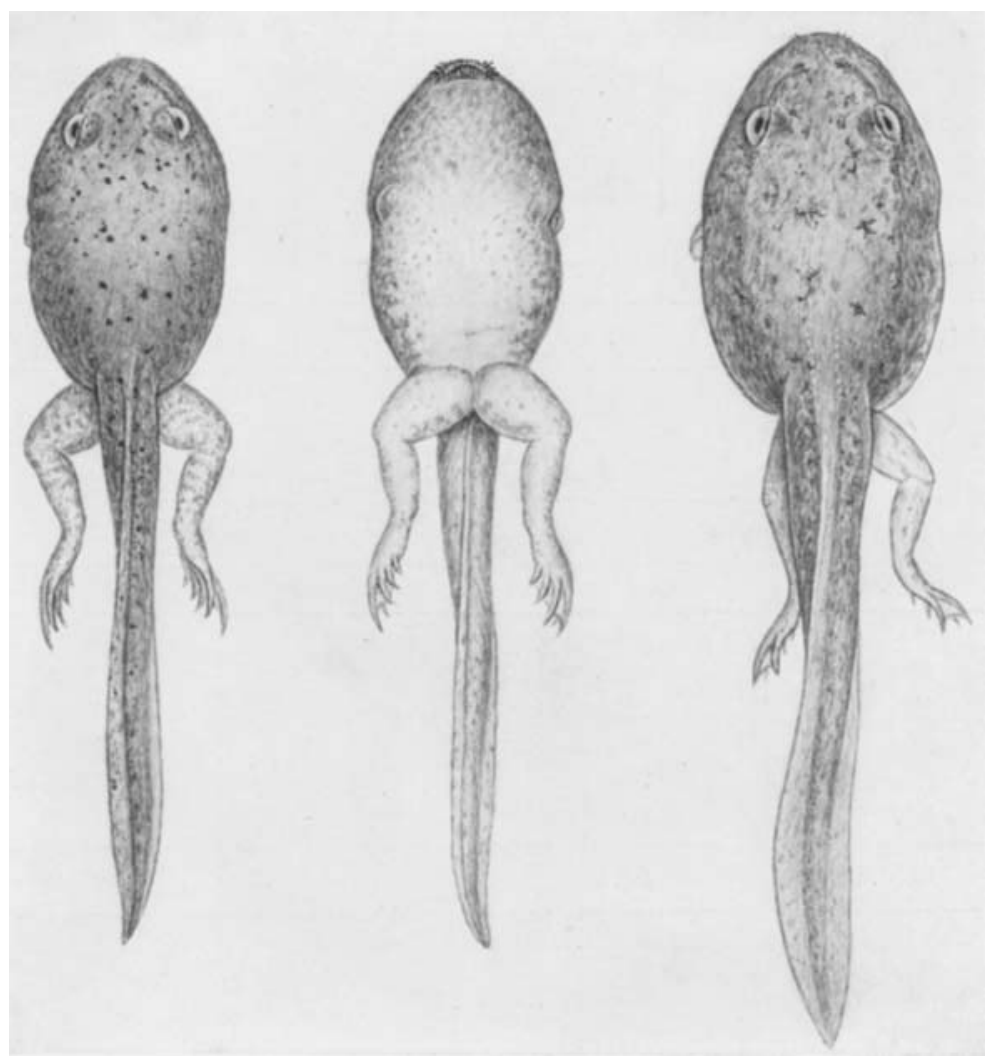

Fig. 2 Neotenous R. clamata tadpoles. Numbers of this type of larvae, measuring 75 to $90 \mathrm{~mm}$. total length, with hind limbs 5 to $25 \mathrm{~mm}$. long, pass an extra year beyond their usual period of metamorphosis in this stage. Drawing natural size.

environment because inhibiting factors could not prevent the release of the contained secretion. The experiment is briefly presented in the following tables: 


\section{TABLE 9}

December 22, 1920

\begin{tabular}{c|c|c|c|c|c}
\hline \multicolumn{2}{c}{ ENGRAFTED } & \multicolumn{2}{c}{$\begin{array}{c}\text { ANIMALs From WHICH GLANDS } \\
\text { WERE TAKEN }\end{array}$} & \multicolumn{2}{|c}{ CONTROLS } \\
\hline Total length & Hind legs & Total length & Hind legs & Total length & Hind legs \\
\hline$m m$. & $m m$. & $m m$. & $m m$. & $m m$. & $m m$. \\
80 & 8.5 & 81 & 8.5 & 81 & 8.5 \\
82 & 10.0 & 82 & 8.5 & 82 & 9.0 \\
83 & 9.0 & 81 & 9 & 80 & 8.0 \\
80 & 8.5 & 80 & 10 & 79 & 8.5 \\
81 & 8.5 & 83 & 8 & 81 & 10.0 \\
82 & 9.0 & 79 & 8.5 & 83 & 8.5 \\
\hline 81.3 & 8.9 & 80.7 & 8.8 & 81 & 8.8 \\
\hline
\end{tabular}

TABIE 10

January 30, 1921

\begin{tabular}{c|c|c|c}
\hline \multicolumn{2}{|c|}{ ENGRAFTED } & \multicolumn{2}{|c}{ control } \\
\hline Total length & Hind legs & Total length & Hind legs \\
\hline$m m$. & $m m$. & $m m$. & $m m$ \\
80 & 25 & 80 & 9.5 \\
82 & 24 & 81 & 10.0 \\
80 & 24 & 82 & 10.0 \\
83 & 23 & 81 & 10.5 \\
82 & 26 & 83 & 10.0 \\
\hline 81.4 & 24.4 & 81.4 & 10.0 \\
\hline
\end{tabular}

Note: One engrafted animal died January 23rd.

TABLE 11

March 1, 1921

\begin{tabular}{c|c|c|c}
\hline \multicolumn{2}{c}{ ENGRAFTED } & \multicolumn{2}{|c}{ ConTrol } \\
\hline Total length & Hind legs & Total length & Hind legs \\
\hline$m m$. & $m m$. & $m m$. & $m m$. \\
83 & 31 & 82 & 13 \\
82 & 32 & 83 & 13 \\
82 & 29 & 81 & 14 \\
84 & 30 & 82 & 12.5 \\
\hline 82.7 & 30.4 & 82 & 13.4 \\
\hline
\end{tabular}


One engrafted animal died February 25th. The experiment was abandoned March 10th, as some of the transplanted individuals had fore limbs. The data clearly indicate that the thyroid glands of neotenous tadpoles with hind legs 8 to $10 \mathrm{~mm}$. are physiologically active and capable of inducing acceleration of limb growth and development when transplanted into other neotenous animals of similar size and developmental stage. However, metamorphic change following grafting is not so rapid or marked as when the same type of gland is implanted in immature (non-neotenous) larvae. But in either case the absorption of the secretion of the grafted gland induced a greater reaction than the same gland is capable of producing (in the same time and under similar conditions) when left unmolested in the neotenous animal of which it was originally a part.

\section{SUMMARY OF CONCLUSIONS}

1. Adult Necturus were fed, injected, and engrafted with physiologically active thyroid substance with negative results. The injection of $20 \mathrm{mg}$. of thyroxin iodine had no effect upon metamorphosis, whereas a 1 to 50,000 solution of this compound readily metamorphosed immature larvae of Amblystoma. The experiment indicates that perennibranchiate amphibians are permanent larvae and have lost the ability to transform under the stimulus of thyroid treatment.

2. Necturus differs markedly from the axolotl in its reaction to thyroid administration, as the latter readily metamorphoses when fed or injected with this substance.

3. The thyroid glands of the perennibranchiate Necturus are quite variable in size, and in some animals may occur as large vesicles more or less isolated from one another. In other individuals the glands are rather small and may consist of but four to six extremely large vesicles. In Necturus the thyroids are generally located near the apex of the triangle formed by the geniohyoid and external ceratohyoid muscies.

4. Despite its larval characters, Necturus possesses thyroid glands of great physiological activity, as shown by heteroplastic transplantation into immature anuran larvae. 
5. A giant axolotl, 14.25 inches long, several years of age, was found to have a highly active metamorphosis-inducing thyroid apparatus. The thyroid of a single specimen cut into six pieces and transplanted metamorphosed five immature anuran tadpoles within two weeks. The sixth animal died following the operation.

6. The axolotl's thyroid is normal in appearance and of large size, consisting of numerous large vesicles filled with colloid. The gland is surrounded by a rich network of capillaries.

7. The failure of the axolotl to metamorphose appears to be due to the inhibition or the defective development of some unknown factor which normally serves to release the fully formed hormone from the thyroid into the blood stream. It is suggested that defective nervous stimulation or perhaps inhibition is the immediate cause of retention of the secretion within the thyroid vesicles, but that in the last analysis some defect of interrelation of the various components of the endocrine system is probably responsible for the nervous inhibition or lack of normal stimulation.

8. Experiments on large neotenous anuran tadpoles indicate that the failure of these animals to metamorphose at the proper time probably is due to the same causes responsible for axolotl neoteny: i.e., the thyroid glands apparently do not secrete their fully formed hormone into the blood stream because of some unknown inhibiting influence. The thyroid inhibition seems to be less marked in anurans than in the axolotl, since neotenous tadpoles eventually metamorphose if given sufficient time.

9. The next step in the analysis of amphibian neoteny is to determine the nature of the factor responsible for the failure of the thyroid to release its hormone (or at any rate to render it impotent in so far as metamorphosis is concerned). Is this unknown factor hormonal, or nervous, or both?

10. In the older work on amphibian neoteny too much stress was laid upon the exogenous factors as causative agents, and too little, if any at all, upon endogenous factors, and heredity. 


\section{ADDENDUM}

Uhlenhuth's claim that urodeles differ from anurans in that their metamorphosis is independent of iodine and influenced only by the thyroid hormone itself is rendered invalid by the following experiment: The thyroid glands of large axolotls (seven inches total length) were extirpated and the animals kept for five months in the laboratory following the operation, then injected twice with strong doses of tyrosine in which two atoms of iodine had been substituted for two hydrogen atoms of the molecule forming the compound 3-5 diiodotyrosine. The animals metamorphosed within seventeen days following injection. Control thyroidless axolotls injected with equal quantities of pure tyrosine and later with large amounts of 3-5 dibromtyrosine showed no evidences of metamorphosis.

Further evidence that Uhlenhuth's claim is not valid is furnished by Huxley and Hogben who metamorphosed Salamandra and Triton larvae by immersion in dilute solutions of iodine (Proc. Roy. Soc., vol. 93, 1922); by Hirschler, who metamorphosed axolotls and tadpoles by administration of elemental iodine and iodoform (Arch. Entw. Mech., 1922), and lastly by Jensen who metamorphosed axolotls by injections of iodized casein, iodized serum globulin and iodized serum albumen (Compt. Rend. Soc. de Biol., 85, 391-392, 1921).

\section{BIBLIOGRAPHY}

AdLer, Leo 1916 Untersuchungen über die Entstehung der Amphibieneotenie. Pflüger's Archiv, Bd. 39.

BRAus, H. 1906 Vordere Extremität und Operculum bei Bombinatorlarven. Morph. Jahrbuch, Bd. 35, Heft 4.

v. Cha Uvin, Marie 1875-76. Über die Verwandlung des mexikanischen Axolotl in Amblystoma. Zeitschr. f. wissensch. Zool., Bd. 25, Suppl., und Bd. 27.

De FilippI 1861 Sulla larva del Triton alpestris. Arch. per la Zool. e per l'Anat. Comp. Genova (quoted from Gadow).

DUmérit, AUgust 1865 Nouvelles observations sur les axolotls nés a la menagerie. Comp. Rend., T. 61.

Emerson, E. T. 1905 General anatomy of Typhlomolge rathbuni. Proc. Soc. Nat. History, Boston, vol. 32 .

Gadow, H. 1909 The Cambridge Natural History, vol. 8. 
HuXley, J. 1920 Metamorphosis of axolotl by thyroid feeding. Nature, vol. 104, no. 2618.

JeNsen, C. O. 1916 Ved Thyroiden-praeparater fremkald Forwardlung tros Axolotll'en. Oversigt. Klg. Danske Vidensk., Selsk. Forhandl., Copenhagen (cited by Uhlenhuth, '21).

KaUfMan, L. 1918 Researches on the artificial metamorphosis of axolotls. Bull. Acad. Sc. Cracon, Ser. B., 32 (cited by Uhlenhuth).

Kollmane, J. 1884 Das U̇berwintern von europäischen Frosch und Tritonlarven und die Umwandlung des mexikanischen Axolotl. Verhandl. d. Naturh. Gesellsch. Basel.

La Ufberger, V. 1913 Ovzbwzeni metamorfos axolotln Krmenim zlazon stitnon. Biologicke Lysty (cited by Adler, '16).

Leydig, Franz 1853 Anatomisch-physiologische Untersuchungen über Fische und Reptilien. Berlin.

SHUFELDT, R.W. 1885 Mexican axolotl and its susceptibility to transformation. Science, vol. 6 .

SwingLe, W.W. 1921 The germ cells of anurans. I. The male sexual cycle of Rana catesbeiana larvae. Jour. Exp. Zoöl., vol. 32, no. 2.

1922 The thyroid glands of the perennibranchiate amphibians. Anat. Rec., vol. 23, no. 1, p. 100, Proc. Am. Soc. Zool.

1922 Experiments with necturus and axolotl thyroids. Anat. Rec., vol. 23, no. 1, p. 106, Proc. Am. Soc. Zool.

UhLENhUth, E. 1921 Internal secretions in growth and development of amphibia. Am. Nat., vol. 55, no. 638.

\section{PLATE 1}

\section{EXPLANATION OF FIGURES}

3 Larva grafted ten days with small piece of Necturus thyroid, and control. 4 and 5 Larvae engrafted eight days with pieces of Necturus thyroid.

6 Larva grafted six days with Necturus thyroid, and normal control.

7 Larva fed mammalian thyroid tissue (desiccated) eight days. Control animal same as in figure 6 . 


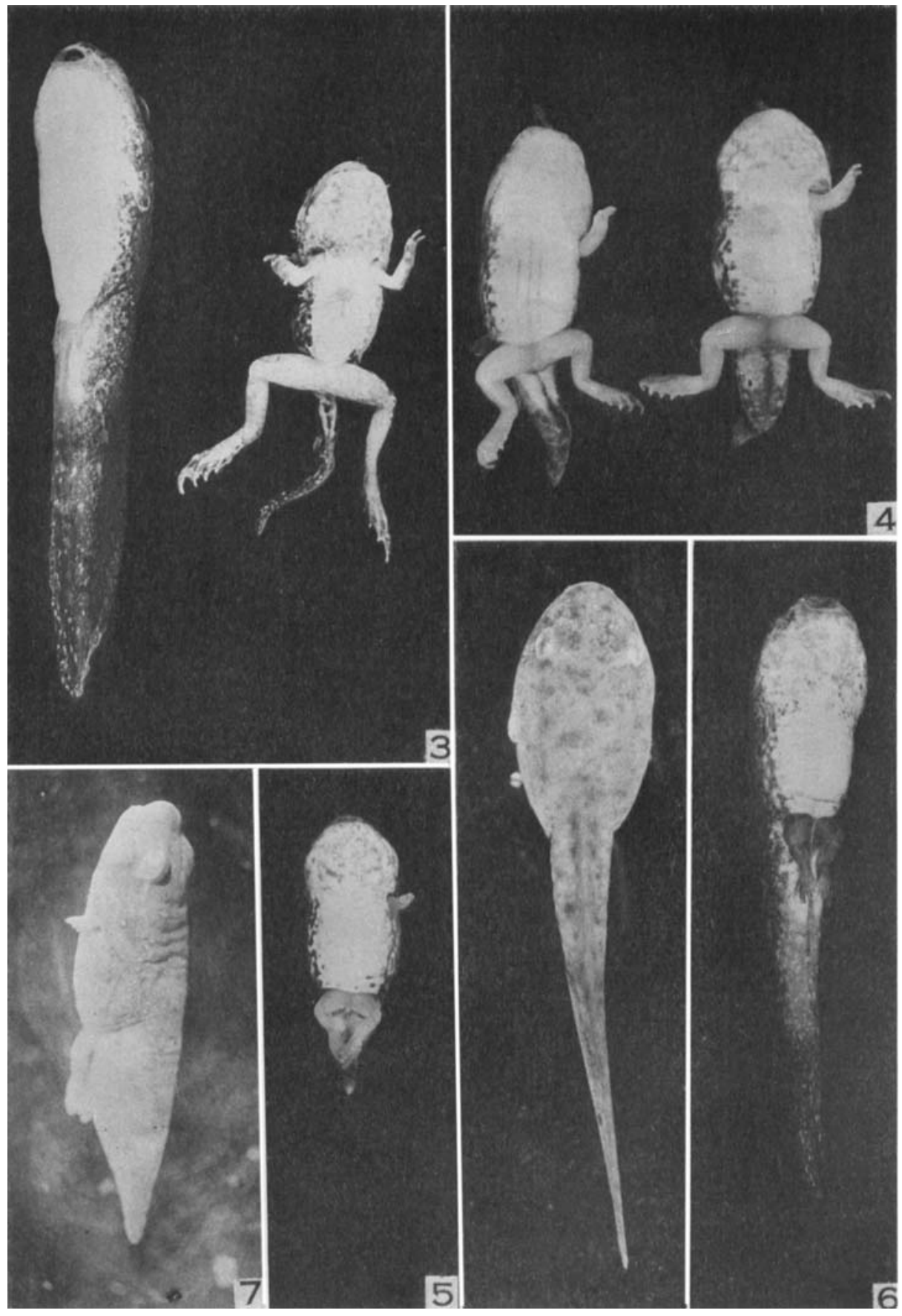




\section{PLATE 2}

\section{EXPLANATION OF FIGURES}

8 Immature $R$. clamata larvac ten days following transplantation small pieces of axolotl thyroids.

9 Same as figure 8. Ventral view.

10 Control larva for animals shown in figures 8 and 9. 

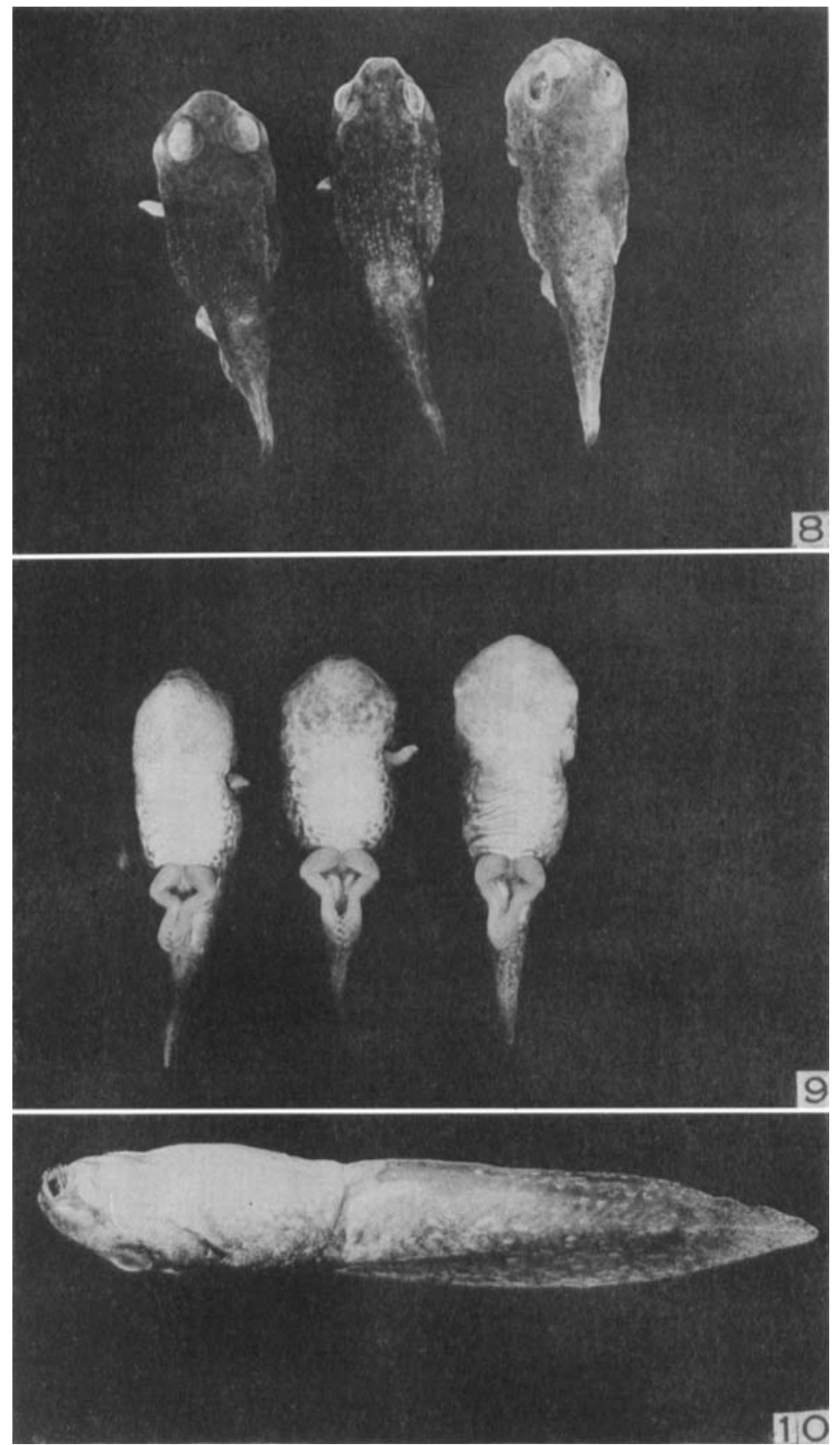